\title{
The Impact of Physical Activity on Cancer Prevention and Survivorship
}

\author{
Takayoshi Yamaga*1, Shuhei Yamamoto ${ }^{1}$ and Matsumori Keiji ${ }^{1}$ \\ ${ }^{1}$ Department of Rehabilitation, Shinshu University Hospital, Nagano, Japan
}

\begin{abstract}
Recently, survival rates for several cancers are increasing as progress is made with therapeutic strategies, leading to an increasing number of cancer survivors. Cancer survivors faced disabilities to daily living can result to decreased physical activity, and this adversely affects the quality of life. Several previous studies have revealed the relationship between cancer and physical activity. Physical activity is very important factor correlated with general health status. Promoting and maintaining physical activity of cancer survivor is a necessary aim in rehabilitation. The results of epidemiological studies have suggested that physical activity is an important therapeutic strategy for delaying relapse and extending life expectancy after a cancer diagnosis, and not just a means of preventing cancer. Promoting physical activity in rehabilitation plays an increasingly important role in the optimization of recovery and symptom control, and palliative and/or prevention of treatment-related toxicity. Physical activity can be important throughout the entire phase from the time of diagnosis to the terminal stage, and promoting physical activity is needed an approach that can involve physical aspects as well as psychosocial aspects.
\end{abstract}

\section{Introduction}

Cancer is expected to affect approximately one in three people currently under the age of 75 in developed countries. According to Global Burden of Disease Study, the incidence of cancer increased by $33 \%$ between 2005 and 2015 [1], and the number of people with cancer around the world is expected to increase by approximately $75 \%$ until 2030, due to changes in demographics and lifestyle, among other factors [2]. Meanwhile, survival rates for several cancers are increasing as progress is made with therapeutic strategies, leading to an increasing number of cancer survivors (people living with the disease long-term). Cancer survivors face disabilities to daily living due to intensive therapy and side effects, as well as disease progression. These disabilities can lead to decreased physical activity (PA) of patients, and this adversely affects the quality of life (QoL) for both patients and their caregivers. In the field of cancer therapy, enhancing or maintaining the PA of survivors is a necessary aim, along with considerations of how to improve QoL.

PA have been understood to be related to the health of cancer patients. A recent meta-analysis investigated the association between PA and risk of mortality due to cancer both in a general population and cancer survivors [3]. That study showed that both members of the general population and cancer survivors with high levels of PA have a lower risk of death from cancer than those with low levels of PA. The findings of that study did not vary between different types of cancer. Rehabilitation of cancer patients is an important intervention for maintaining or enhancing QoL and PA, and the purpose and content of this intervention needs to be adjusted according to disease stage [4]. However, PA is an important indicator of mortality risk at any time, including periods when the focus is on disease prevention, and targets need to be set for maintenance or enhancement of PA. In this review, we discuss previous research on PA and cancer.

\section{Physical activity correlate with general health status}

PA is defined as any bodily movement produced by skeletal muscles that results in energy expenditure. Exercise is a subset of physical activity that is planned, structured, and repetitive and has as a final or an intermediate objective the improvement or maintenance of physical fitness [5]. PA is reported to be associated with many chronic diseases, not just cancer. Such a relationship was first described for heart disease [6], followed by diabetes, obesity, bone and joint disease, and other chronic disorders including depression [7]. Previous research suggested that PA is effective in lowering mortality risk, and over 1.3 million deaths/year could be avoided with a $25 \%$ increase in PA [8]. The prime importance of PA for health is indicated in the 2008 Physical Activity Guidelines for Americans which state that weekly aerobic exercise of at least 150 to $300 \mathrm{~min}$ at moderate intensity, or 75 to $150 \mathrm{~min}$ at vigorous intensity, will produce significant health benefits. However, improved health status and longer life expectancy is known to result from even a small amount of exercise, which may contribute to reduced medical costs and treatment disparities [9].

Recently, there have been moves to assess PA in conjunction with physical inactivity, which is regarded as sedentary behavior (SB) [10]. SB is defined as "waking behavior such as sitting, lying down, and expending very little energy (approximately 1.0-1.5 metabolic equivalents (MET)" [11] and is classified separately from insufficient PA. The relationship between PA and SB can be represented diagrammatically (Figure). Previous research has been conducted in the United States and Australia on the amount of time adults spend in PA and SB during their waking hours [12]. The results showed that adults spend only $5 \%$ of their waking hours engaged in moderate- to vigorousintensity PA, a form of activity that had received much attention prior

Correspondence to: Takayoshi Yamaga, Department of Rehabilitation, Shinshu University Hospital, Nagano, Japan, Tel: +81-263-37-2836; Fax: +81-263-372835; E-mail: serisaito@shinshu-u.ac.jp

Key words: physical activity, cancer, cancer prevention, cancer rehabilitation

Received: March 02, 2017; Accepted: March 21, 2017; Published: March 24 2017 


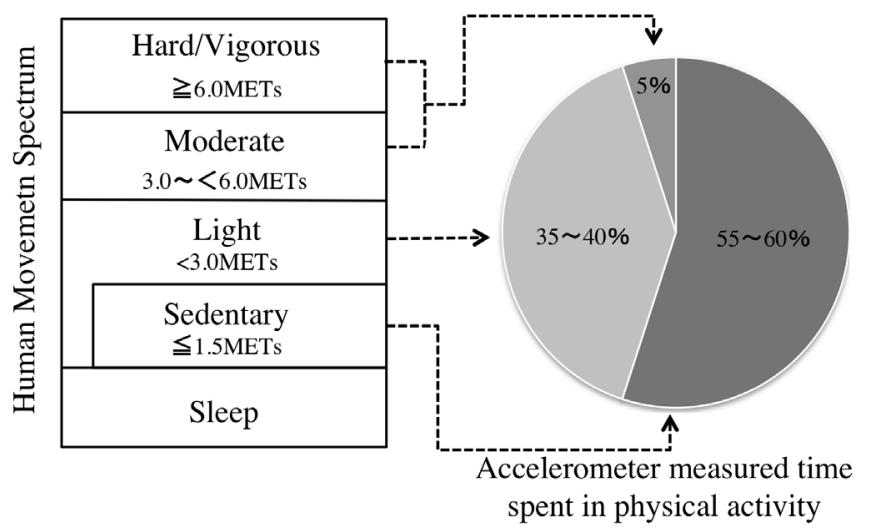

Figure. Defining PA as part of the human movement spectrum and time spend in PA of the day.

Source: Baced on Dunstan et al.[12] and Gibbs et al. [79]

to this study, and that light-intensity PA (35\%-40\%) and SB (55\%$60 \%$ ) occupy the larger proportion of waking hours. A notable study showed that increased SB was associated with increased mortality rate, independent of PA [13]. Furthermore, a recent meta-analysis showed that SB was associated with a lower mortality rate in people with high levels of PA [hazard ratio (HR) of 1.46; 95\% confidence interval (CI): 1.22 to 1.75 ] than those with low levels of PA [HR of $1.16,95 \% \mathrm{CI}$ : 0.84 to 1.59]. Other research has shown that 8 hours of consecutive SB can be offset by $60 \mathrm{~min}$ of PA [14], and interventions need to focus on reducing $\mathrm{SB}$, not just increasing $\mathrm{PA}$

\section{Effects of physical activity on cancer prevention}

Many studies dating back over 90 years have investigated cancer prevention $[15,16]$. PA reduces the risk of developing cancer across a wide range of the population, irrespective of sex and type of PA [17]. The 2006 American Cancer Society (ACS) cancer prevention guidelines recommend $30 \mathrm{~min}$, or preferably 45 to $60 \mathrm{~min}$, of moderate-intensity (or greater) PA at least 5 days a week, for the prevention of cancer [18]. Preventive effects of PA are described extensively in the literature on breast and colorectal cancer. A comparison of PA measurements in adults revealed that a dose response was seen in the reduction in the risk of developing cancer at higher levels of PA (600-3,999 METs minutes/week and 4,000-7,999 METs minutes/week vs. $<600$ METs minutes/week), with risk reduction ranging from $3 \%$ to $14 \%$ for breast cancer and $10 \%$ to $21 \%$ for colorectal cancer [19]. Increased PA has also been described as beneficial for post-menopausal women diagnosed with breast cancer, and the timing of initiating exercise is also important [20]. The risk of gastric cancer was found to be $21 \%$ lower in persons with high levels of PA than in those with low levels of PA [21]. Regarding other cancers, the relative risk reduction for persons with high levels of PA (versus those with low levels) was $42 \%$ for gastrointestinal cancer, 23\% for renal cancer, and 20\% for myeloid leukemia, and PA had a preventive effect against a wide range of cancers [22]. Current guidelines recommend $150 \mathrm{~min}$ of PA weekly in order to experience substantial health benefit. However, the incidence of cancer is significantly reduced even at half the recommended level, an average of 15 min PA per day [9]. This shows that almost all loss of $\mathrm{PA}$ is highly deleterious, and that moderate-intensity activity, even in small amounts, is beneficial. Even light-intensity PA can be important in preventing cancer [23], and this is possibly because increases in light-intensity PA are related to relative reductions in SB. A metaanalysis of relationships between $\mathrm{SB}$ and cancer suggested that $\mathrm{SB}$ was associated with overall cancer risk and with the risk of uterine cancer, colon cancer, breast cancer, and lung cancer, specifically [24].

The mechanisms underlying the anti-cancer effects of PA remain unclear although various hypotheses exist. These include preventing genetic damage, promoting immune function, suppressing chronic inflammation, and preventing overproduction of insulin and insulinlike growth factors, with resultant inhibition of cancer cell proliferation. PA probably inhibits the emergence and proliferation of cancer cells through multiple mechanisms and complex associations [25].

The 2012 ACS guideline [26] recommend daily PA with a resumption of normal daily activity as soon as possible after diagnosis and the avoidance of inactivity. This recommendation is for $150 \mathrm{~min}$ of moderate-intensity PA, including some muscle strength training, twice a week. PA is also important during treatment following diagnosis, and after the end of treatment. A meta-analysis revealed that PA during therapy was related to physical stamina, muscle strength, body weight, anxiety level, self-respect, QoL, insulin-like growth factor (IGF)-1, and cancer-related symptoms [27]. Furthermore, his meta-analysis revealed no adverse events and exercise was found to be safe.

\section{Effects of physical activity for cancer survivors}

Many studies have demonstrated the effectiveness of PA during treatment. Numerous reports indicate that increased PA by exercisebased cancer rehabilitation during and after cancer therapy shortens hospital stay, reduces the risk of complications, and is associated with enhanced physical function and QoL. In patients with breast and head and neck cancer who received surgical treatment, higher levels of PA and reduced shoulder pain have been reported with a postoperative rehabilitation regime that includes exercise [28]. In colorectal cancer, shorter hospital stays and lower incidence of postoperative complications have been reported with early ambulation and provision of nutrition therapy postoperatively aimed at increasing PA $[29,30]$. In stomach cancer, shorter hospital stays, lower hospital costs, and reduced postoperative complications have been reported with a comprehensive approach to care including enhanced PA [31]. A recent study of colorectal and breast cancer patients with high levels of preoperative PA showed high postoperative recovery of physical function [32,33], and PA is an important factor before and after surgery. PA is also important before and after chemotherapy and radiotherapy; a substantial adverse effect on daily life may follow a decline in muscle strength and exercise tolerance with low levels of PA pre- or post-therapy [34]. Accordingly, PA can be maintained, and maximum walking speed, muscle strength, and body composition can be maintained or improved when the patient exercises [35-38].

Cancer survivors clearly experience a marked decline in PA due to treatment, and this effect persists after treatment has ended [39]; around $16 \%-20 \%$ of all cancer survivors engage in regular PA [40]. Physical fitness is known to affect PA and this association has been investigated in cancer survivors. The results of this investigation show a reduced mortality risk with higher physical fitness for cancer overall and for various types of cancer specifically (Table) [8,41-51]. Increased $\mathrm{PA}$ is associated with lower cancer-related and all-cause mortality rates in cancer survivors, and PA showed a suppressive effect on mortality rate [52-54]. The efficacy of PA has been demonstrated with endpoints other than mortality rate. Moderate-intensity PA has been shown to contribute to improved body weight, body mass index, maximum oxygen consumption, maximum work rate, distance covered in the 6min walk test, muscle strength, levels of fatigue and depression, and QoL $[27,55,56]$. 
Table. Cohort study on physical fitness and cancer mortality.

\begin{tabular}{|c|c|c|c|c|c|c|c|}
\hline Source & Year & Sex & $\begin{array}{l}\text { Number of } \\
\text { participants }\end{array}$ & Diagnosis & $\begin{array}{c}\text { Follow-up } \\
\text { (years) }\end{array}$ & Death & $\begin{array}{c}\text { RR/HR }(95 \% \mathrm{CI}) \\
\text { (The highest category of } \\
\text { physical fitness) }\end{array}$ \\
\hline Blair et al. & 1989 & Men* & 10224 & Mixed & 8 & 64 & \\
\hline kampertet al. & 1996 & Men* & 25341 & Mixed & 8 & 179 & $\mathrm{RR}: 0.36(0.21$ to 0.61$)$ \\
\hline Lee $e t a l$. & 2002 & Men & 25802 & Mixed & 10 & 335 & $\mathrm{RR}: 0.45(0.34$ to 0.61$)$ \\
\hline Sawada et al. & 2003 & Men & 9039 & Mixed & 16 & 123 & $\mathrm{RR}: 0.41(0.23$ to 0.74$)$ \\
\hline Evensonet al. & 2003 & Men* & 2890 & Mixed & 25 & 401 & HR : $0.41(0.23$ to 0.75$)$ \\
\hline Farrell et al. & 2007 & Men & 38410 & Mixed & 17 & 1037 & HR : $0.53(0.43$ to 0.67$)$ \\
\hline Thompson et al. & 2008 & Men & 18858 & Mixed & 16 & 719 & HR : $0.70(0.56$ to 0.86$)$ \\
\hline Peel et al. & 2009 & Men & 38801 & Mixed & 29 & 556 & HR : $0.56(0.40$ to 0.80$)$ \\
\hline Peel et al. & 2009 & Women & 14811 & Brest & 16 & 68 & HR : 0.45 (0.22 to 0.95$)$ \\
\hline Laukkanenet al. & 2010 & Men & 2268 & Mixed & 17 & 159 & $\mathrm{RR}: 0.55(0.36$ to 0.83$)$ \\
\hline Sui et al. & 2010 & Men & 38000 & Lung & 17 & 232 & HR : $0.43(0.28$ to 0.65$)$ \\
\hline Lakoskiet al. & 2015 & Men & 13949 & Mixed & 10 & 281 & HR : $0.66(0.48$ to 0.91$)$ \\
\hline
\end{tabular}

"The women in that study were statistically non-significant results

${ }^{* *}$ The lowest category of physical fitness is reference

Cancer survivors who receive palliative care experience deterioration in their general condition [57]. This is accompanied with decreased activities of daily living due to impaired physical function, or another physical or psychiatric condition; treatment costs are also increased [58-61]. During this period, the goal is to enhance QoL for patients and their families, and for patients with terminal disease, to increase physical and mental well-being [62]. PA can potentially mitigate pain, fatigue, and insomnia in cancer survivors receiving palliative care [63]. Proactive maintenance or enhancement of PA is desirable; however, PA becomes difficult due to cancer progression and associated cachexia. Generally, in the absence of moderate- to vigorousintensity PA, low-intensity PA can reduce the risk of complications and disease progression [64], and thus patients should be encouraged to undertake PA to the maximum extent possible. Engaging in PA appropriate for the patient's condition can reduce healthcare costs, improve physical function, and maintain QoL. However, in contrast to the reported association between PA and QoL in the palliative phase [65], greater physical function resulting from increased PA had no effect on general condition in patients with metastatic breast cancer involved in a PA enhancement program [66]. Furthermore, another study revealed that PA had no effect on physical function or QoL in the palliative care phase [67]. Considering these findings, some cancer survivors may experience difficulties in keeping up with moderate-intensity PA. For such patients, the perspective should shift to interventions which increase low-intensity $\mathrm{PA}$ and reduce $\mathrm{SB}$, rather than intensify PA. However, it is currently unclear where to set the threshold for SB in order to achieve health outcomes. The effectiveness of replacing walking and standing exercises with low-intensity PA is also unclear. Accordingly, further research is needed to establish if SB has any dose-response relationship with health outcomes and to investigate the effects of reducing SB. The indications for increased PA in patients during the palliative care phase may vary depending on the previous course of treatment and the current physical and mental state. Accordingly, further research is needed on the various areas where the effect of PA is unclear.

\section{Determinants of physical activity in cancer survivors}

Identifying possible determinants of PA is important for achieving an increase in PA or a reduction in SB. Reported emotional and psychological determinants of PA in cancer survivors are distress and loss of willpower due to cancer-related symptoms, fatigue, enjoyment of PA, a sense of purpose, and self-efficacy [68-70]. Exercise interventions designed to enhance or maintain PA can come up against barriers. These barriers must be understood, strategies for overcoming them must be devised, and the setting and method of the intervention must be considered. Maintaining or enhancing PA is important no matter what activity is engaged in and various group activity programs have been analyzed in a previous investigation $[71,72]$. In that research, cancer survivors showed interest in information about PA. Furthermore, several factors have been identified as determining preference for and interest in such a program including age, current level of PA, educational history, income, obesity, stage of cancer, time elapsed since diagnosis, type of treatment, and comorbidity [40,68,7376]. Other factors are self-efficacy, enjoyment of PA, social support, sensory disturbance, depression, and fatigue [75,77]. Instituting PAenhancing interventions requires that patients be made aware of the therapeutic purpose, and that patients are interested in the selected activity, and have the capability, opportunity, and inclination to perform it.

\section{Conclusions}

We have reviewed cancer and PA, which is an important indicator for cancer rehabilitation. Some cancers are completely curable, but many are progressive. Cancer survivors face limitations of extended PA due to the disease and the effects of treatment, and this can lead to further symptoms and atrophy. Promoting PA plays an increasingly important role in the optimization of recovery and symptom control, and palliative and/or prevention of treatment-related toxicity. The results of many epidemiological studies have suggested that PA is an important therapeutic strategy for delaying relapse and extending life expectancy after a cancer diagnosis, and not just a means of preventing cancer. Methods for increasing PA are not a uniform mode of intervention because the objectives vary with the type of cancer and the stage of disease. The physiological mechanism by which exercisecentered PA produces health benefits is not clearly understood. A few hypotheses have been advanced, encompassing areas such as regulation of sex hormones, insulin, and IGF-1, improved regulation of immunological function, and inhibition of free radical production. No precise demonstration has been possible for any of the theoretical mechanisms. In contrast, excessively vigorous exercise may be linked to increases in reactive oxygen species and free radicals, and damage to lipids, proteins, and DNA. These details require attention because PA has the potential to be either harmful or beneficial, and these interventions for cancer survivors at risk of disadvantage should 
be carried out under the supervision of a specialist. It also remains unclear whether an increase in PA or a decrease in SB has greater utility for cancer survivors. However, PA and SB can now each be evaluated with a four-category (Physically Active and Low Sedentary, Physically Active and High Sedentary, Physically Inactive and Low Sedentary and Physically Inactive and High Sedentary) classification [78], and guidance on health risk reduction is needed, even if the risk reduction is small. This requires consideration of the disease, patient needs, capabilities, and preferences, as well as designing tailor-made interventions. Guidelines need to be developed for planning PA enhancement and SB reduction, together with details such as the form, frequency, level, and duration of PA. In rehabilitation, PA should be used as an important indicator because it improves prognosis and alleviates symptoms at any stage of cancer.

\section{References}

1. Global Burden of Disease Cancer C, Fitzmaurice C, Allen C, Barber RM, Barregard L, Bhutta ZA, et al. (2016) Global, Regional, and National Cancer Incidence, Mortality, Years of Life Lost, Years Lived With Disability, and Disability-Adjusted Life-years for 32 Cancer Groups, 1990 to 2015: A Systematic Analysis for the Global Burden of Disease Study. JAMA Oncol.

2. Bray F, Jemal A, Grey N, Ferlay J, Forman D (2012) Global cancer transitions according to the Human Development Index (2008-2030): a population-based study. Lancet Oncol 13:790-801. [Crossref]

3. Li T, Wei S, Shi Y, Pang S, Qin Q, et al. (2016) The dose-response effect of physical activity on cancer mortality: findings from 71 prospective cohort studies. Br J Sports Med 50: 339-345. [Crossref]

4. Dietz JH Jr (1969) Rehabilitation of the cancer patient. Med Clin North Am 53: 607624. [Crossref]

5. Caspersen CJ, Powell KE, Christenson GM (1985) Physical activity, exercise, and physical fitness: definitions and distinctions for health-related research. Public Health Rep 100:126-31. [Crossref]

6. Morris JN, Crawford MD (1958) Coronary heart disease and physical activity of work; evidence of a national necropsy survey. Br Med J 2: 1485-1496. [Crossref]

7. Warburton DE, Nicol CW, Bredin SS (2006) Health benefits of physical activity: the evidence. CMAJ 174: 801-809. [Crossref]

8. Lee CD, Blair SN (2002) Cardiorespiratory fitness and smoking-related and total cancer mortality in men. Med Sci Sports Exerc 34: 735-739. [Crossref]

9. Wen CP, Wai JP, Tsai MK, Yang YC, Cheng TY, Lee MC, et al. (2011) Minimum amount of physical activity for reduced mortality and extended life expectancy: a prospective cohort study. Lancet 378:1244-53. [Crossref]

10. Pate RR, O'Neill JR, Lobelo F (2008) The evolving definition of "sedentary". Exerc Sport Sci Rev 36: 173-178. [Crossref]

11. Ainsworth BE, Haskell WL, Whitt MC, Irwin ML, Swartz AM, et al. (2000) Compendium of physical activities: an update of activity codes and MET intensities. Med Sci Sports Exerc 32: S498-504. [Crossref]

12. Dunstan DW1, Howard B, Healy GN, Owen N (2012) Too much sitting--a health hazard. Diabetes Res Clin Pract 97: 368-376. [Crossref]

13. Biswas A, Oh PI, Faulkner GE, Bajaj RR, Silver MA, et al. (2015) Sedentary time and its association with risk for disease incidence, mortality, and hospitalization in adults: a systematic review and meta-analysis. Ann Intern Med 162: 123-132. [Crossref]

14. Ekelund U, Steene-Johannessen J, Brown WJ, Fagerland MW, Owen N, et al. (2016) Does physical activity attenuate, or even eliminate, the detrimental association of sitting time with mortality? A harmonised meta-analysis of data from more than 1 million men and women. Lancet 388: 1302-1310. [Crossref]

15. Cherry T (1922) A theory of cancer. Medical Journal of Australia1:425-38.

16. Sivertsen I, Dahlstrom AW (1921)The Relation of Muscular Activity to Carcinoma: A Preliminary Report.The Journal of Cancer Research 6:365-78.

17. Inoue M, Yamamoto S, Kurahashi N, Iwasaki M, Sasazuki S, Tsugane S, et al. (2008) Daily total physical activity level and total cancer risk in men and women: results from a large-scale population-based cohort study in Japan. Am J Epidemiol 168:391-403. [Crossref]
18. Doyle C, Kushi LH, Byers T, Courneya KS, Demark-Wahnefried W, et al. (2006) Nutrition and physical activity during and after cancer treatment: an American Cancer Society guide for informed choices. CA Cancer J Clin 56:323-53. [Crossref]

19. Kyu HH, Bachman VF, Alexander LT, Mumford JE, Afshin A, et al. (2016) Physical activity and risk of breast cancer, colon cancer, diabetes, ischemic heart disease, and ischemic stroke events: systematic review and dose-response meta-analysis for the Global Burden of Disease Study 2013. BMJ 354:i3857. [Crossref]

20. Eliassen A, Hankinson SE, Rosner B, Holmes MD, Willett WC (2010)Physical activity and risk of breast cancer among postmenopausal women. Arch Intern Med 170:1758 64. [Crossref]

21. Singh S, EdakkanambethVarayil J, Devanna S, Murad MH, Iyer PG (2014) Physical activity is associated with reduced risk of gastric cancer: a systematic review and metaanalysis. Cancer Prev Res (Phila) 7: 12-22. [Crossref]

22. Moore SC, Lee IM2, Weiderpass E3, Campbell PT4, Sampson JN1, et al. (2016) Association of Leisure-Time Physical Activity With Risk of 26 Types of Cancer in 1.44 Million Adults. JAMA Intern Med 176: 816-825. [Crossref]

23. Hupin D, Roche F, Gremeaux V, Chatard JC, Oriol M, et al. (2015) Even a low-dose of moderate-to-vigorous physical activity reduces mortality by $22 \%$ in adults aged $>/=60$ years: a systematic review and meta-analysis. Br J Sports Med 49:1262-7. [Crossref]

24. Shen D, Mao W, Liu T, Lin Q, Lu X, et al. (2014) Sedentary behavior and incident cancer: a meta-analysis of prospective studies. PLoS One 9: e105709.[Crossref]

25. McTiernan A (2008) Mechanisms linking physical activity with cancer. Nat Rev Cancer 8: 205-211. [Crossref]

26. Rock CL, Doyle C, Demark-Wahnefried W, Meyerhardt J, Courneya KS, et al. (2012) Nutrition and physical activity guidelines for cancer survivors. CA Cancer J Clin 62: 243-274. [Crossref]

27. Speck RM, Courneya KS, Masse LC, Duval S, Schmitz KH (2010)An update of controlled physical activity trials in cancer survivors: a systematic review and metaanalysis. J Cancer Surviv 4:87-100. [Crossref]

28. Salerno G, Cavaliere M, Foglia A, Pellicoro DP, Mottola G, et al. (2002) The 11th nerve syndrome in functional neck dissection. Laryngoscope 112: 1299-1307. [Crossref]

29. Adamina M, Kehlet H, Tomlinson GA, Senagore AJ, Delaney CP (2011) Enhanced recovery pathways optimize health outcomes and resource utilization: a meta-analysis of randomized controlled trials in colorectal surgery. Surgery 149:830-40. [Crossref]

30. Gouvas N1, Tan E, Windsor A, Xynos E, Tekkis PP (2009) Fast-track vs standard care in colorectal surgery: a meta-analysis update. Int J Colorectal Dis 24: 1119-1131. [Crossref]

31. Feng F, Ji G, Li JP, Li XH, Shi H, et al. (2013) Fast-track surgery could improve postoperative recovery in radical total gastrectomypatients. World $J$ Gastroenterol 19:3642-8. [Crossref]

32. Onerup A, Bock D, Borjesson M, Fagevik Olsen M, Gellerstedt M, et al. (2016) Is preoperative physical activity related to post-surgery recovery?-a cohort study of colorectal cancer patients. Int J Colorectal Dis 31:1131-40. [Crossref]

33. Nilsson H, Angeras U, Bock D, Borjesson M, Onerup A, et al. (2016) Is preoperative physical activity related to post-surgery recovery? A cohort study of patients with breast cancer. BMJ Open 6:e007997. [Crossref]

34. Fobair P, Hoppe RT, Bloom J, Cox R, Varghese A, et al. (1986) Psychosocial problems among survivors of Hodgkin's disease. J Clin Oncol 4: 805-814. [Crossref]

35. Hayes S, Davies PS, Parker T, Bashford J (2003) Total energy expenditure and body composition changes following peripheral blood stem cell transplantation and participation in an exercise programme. Bone Marrow Transplant 31:331-8. [Crossref]

36. Mello M, Tanaka C, Dulley FL (2003) Effects of an exercise program on muscle performance in patients undergoing allogeneic bone marrow transplantation. Bone Marrow Transplant 32:723-8. [Crossref]

37. Dimeo FC, Tilmann MH, Bertz H, Kanz L, Mertelsmann R, et al. (1997) Aerobic exercise in the rehabilitation of cancer patients after high dose chemotherapy and autologous peripheral stem cell transplantation. Cancer 79: 1717-22. [Crossref]

38. Adamsen L, Quist M, Andersen C, Moller T, Herrstedt J, et al. (2009) Effect of a multimodal high intensity exercise intervention in cancer patients undergoing chemotherapy: randomised controlled trial. BMJ 339:b3410. [Crossref]

39. Jones LW, Courneya KS, Vallance JK, Ladha AB, Mant MJ, et al. (2004) Association between exercise and quality of life in multiple myeloma cancer survivors. Support Care Cancer 12:780-8. [Crossref] 
40. Jones LW, Courneya KS (2002) Exercise counseling and programming preferences of cancer survivors. Cancer Pract 10: 208-215. [Crossref]

41. Blair SN, Kohl HW 3rd, Paffenbarger RS Jr, Clark DG, Cooper KH, et al. (1989) Physical fitness and all-cause mortality. A prospective study of healthy men and women. JAMA 262: 2395-2401. [Crossref]

42. Kampert JB, Blair SN, Barlow CE, Kohl HW 3rd (1996) Physical activity, physical fitness, and all-cause and cancer mortality: a prospective study of men and women. Ann Epidemiol 6: 452-457. [Crossref]

43. Sawada SS, Muto T, Tanaka H, Lee IM, Paffenbarger RS Jr, et al. (2003) Cardiorespiratory fitness and cancer mortality in Japanese men: a prospective study. Med Sci Sports Exerc 35: 1546-1550. [Crossref]

44. Evenson KR, Stevens J, Cai J, Thomas R, Thomas O (2003) The effect of cardiorespiratory fitness and obesity on cancer mortality in women and men. Med Sci Sports Exerc 35: 270-277. [Crossref]

45. Farrell SW, Cortese GM, LaMonte MJ, Blair SN (2007) Cardiorespiratory fitness, different measures of adiposity, and cancer mortality in men. Obesity (Silver Spring) 15:3140-9. [Crossref]

46. Thompson AM, Church TS, Janssen I, Katzmarzyk PT, Earnest CP, et al. (2008) Cardiorespiratory fitness as a predictor of cancer mortality among men with prediabetes and diabetes. Diabetes Care 31: 764-769. [Crossref]

47. Peel JB, Sui X, Adams SA, Hébert JR, Hardin JW, et al. (2009) A prospective study of cardiorespiratory fitness and breast cancer mortality. Med Sci Sports Exerc 41: 742748. [Crossref]

48. Peel JB, Sui X, Matthews CE, Adams SA, Hebert JR, et al. (2009) Cardiorespiratory fitness and digestive cancer mortality: findings from the aerobics center longitudinal study. Cancer Epidemiol Biomarkers Prev 18:1111-7. [Crossref]

49. Laukkanen JA, Pukkala E, Rauramaa R, Mäkikallio TH, Toriola AT, et al. (2010) Cardiorespiratory fitness, lifestyle factors and cancer risk and mortality in Finnish men. Eur J Cancer 46: 355-363. [Crossref]

50. Sui X, Lee DC, Matthews CE, Adams SA, Hébert JR, et al. (2010) Influence of cardiorespiratory fitness on lung cancer mortality. Med Sci Sports Exerc 42: 872-878. [Crossref]

51. Lakoski SG, Willis BL, Barlow CE, Leonard D, Gao A, et al. (2015) Midlife Cardiorespiratory Fitness, Incident Cancer, and Survival After Cancer in Men: The Cooper Center Longitudinal Study. JAMA Oncol 1:231-7. [Crossref]

52. Holmes MD, Chen WY, Feskanich D, Kroenke CH, Colditz GA (2005) Physical activity and survival after breast cancer diagnosis. JAMA 293: 2479-2486. [Crossref]

53. Lahart IM, Metsios GS, Nevill AM, Carmichael AR (2015) Physical activity, risk of death and recurrence in breast cancer survivors: A systematic review and meta-analysis of epidemiological studies. Acta Oncol 54: 635-654. [Crossref]

54. Li Y, Gu M, Jing F, Cai S, Bao C, et al. (2016) Association between physical activity and all cancer mortality: Dose-response meta-analysis of cohort studies. Int J Cancer 138:818-32. [Crossref]

55. Fong DY, Ho JW, Hui BP, Lee AM, Macfarlane DJ, et al. (2012) Physical activity for cancer survivors: meta-analysis of randomised controlled trials. BMJ 344: e70. [Crossref]

56. Jones LW, Liang Y, Pituskin EN, Battaglini CL, Scott JM, et al. (2011) Effect of exercise training on peak oxygen consumption in patients with cancer: a meta-analysis. Oncologist 16: 112-120. [Crossref]

57. Seow H, Barbera L, Sutradhar R, Howell D, Dudgeon D, et al. (2011) Trajectory of performance status and symptom scores for patients with cancer during the last six months of life. J Clin Oncol 29: 1151-1158. [Crossref]

58. Stafford RS, Cyr PL (1997) The impact of cancer on the physical function of the elderly and their utilization of health care.Cancer 80: 1973-1980. [Crossref]

59. Baker F, Haffer SC, Denniston M (2003) Health-related quality of life of cancer and noncancer patients in Medicare managed care. Cancer 97:674-81. [Crossref]
60. Hewitt M, Rowland JH, Yancik R (2003) Cancer survivors in the United States: age, health, and disability. J Gerontol A Biol Sci Med Sci 58: 82-91. [Crossref]

61. Torvinen S, Färkkilä N, Sintonen H, Saarto T, Roine RP, et al. (2013) Health-related quality of life in prostate cancer. Acta Oncol 52: 1094-1101. [Crossref]

62. Morrison RS, Meier DE (2004) Clinical practice. Palliative care. N Engl J Med 350: 2582-2590. [Crossref]

63. Roh SY, Yeom HA, Lee MA, Hwang IY (2014) Mobility of older palliative care patients with advanced cancer: a Korean study. Eur J Oncol Nurs 18: 613-618. [Crossref]

64. Dunlop DD, Song J, Semanik PA, Sharma L, Bathon JM, et al. (2014) Relation of physical activity time to incident disability in community dwelling adults with or at risk of knee arthritis: prospective cohort study. BMJ 348: g2472. [Crossref]

65. Lowe SS, Watanabe SM, Baracos VE, Courneya KS (2009) Associations between physical activity and quality of life in cancer patients receiving palliative care: a pilot survey. J Pain Symptom Manage 38:785-96. [Crossref]

66. Oldervoll LM, Loge JH, Lydersen S, Paltiel H, Asp MB, et al. (2011) Physical Exercise for Cancer Patients with Advanced Disease: A Randomized Controlled Trial. Oncologist 16:1649-57. [Crossref]

67. Ligibel JA, Giobbie-Hurder A, Shockro L, Campbell N, Partridge AH, et al. (2016) Randomized trial of a physical activity intervention in women with metastatic breas cancer. Cancer 122:1169-77. [Crossref]

68. Courneya KS, McKenzie DC, Reid RD, Mackey JR, Gelmon K, et al. (2008) Barriers to supervised exercise training in a randomized controlled trial of breast cancer patients receiving chemotherapy. Ann Behav Med 35:116-22. [Crossref]

69. Perna FM, Craft L, Carver CS, Antoni MH (2008) Negative affect and barriers to exercise among early stage breast cancer patients. Health Psychol 27:275-9. [Crossref]

70. Whitehead S, Lavelle K (2009) Older breast cancer survivors' views and preferences for physical activity. Qual Health Res 19: 894-906. [Crossref]

71. Belanger LJ, Plotnikoff RC, Clark A, Courneya KS (2012) A survey of physical activity programming and counseling preferences in young-adult cancer survivors. Cancer Nurs 35:48-54. [Crossref]

72. Vallance JK, Courneya KS, Jones LW, Reiman T (2006) Exercise preferences among a population-based sample of non-Hodgkin's lymphoma survivors. Eur J Cancer Care (Engl) 15: 34-43. [Crossref]

73. Jones LW, Guill B, Keir ST, Carter K, Friedman HS, et al. (2007) Exercise interest and preferences among patients diagnosed with primary brain cancer. Support Care Cancer 15:47-55. [Crossref]

74. Karvinen KH, Courneya KS, Campbell KL, Pearcey RG, Dundas G, et al. (2006) Exercise preferences of endometrial cancer survivors: a population-based study. Cancer Nurs 29: 259-265. [Crossref]

75. Rogers LQ, Courneya KS, Verhulst S, Markwell SJ, McAuley E (2008) Factors associated with exercise counseling and program preferences among breast cancer survivors. J Phys Act Health 5:688-705. [Crossref]

76. Trinh L, Plotnikoff RC, Rhodes RE, North S, Courneya KS (2012) Physical activity preferences in a population-based sample of kidney cancer survivors. Support Care Cancer 20:1709-17. [Crossref]

77. Rogers LQ, Markwell SJ, Verhulst S, McAuley E, Courneya KS (2009)Rural breast cancer survivors: exercise preferences and their determinants. Psychooncology 18:41221. [Crossref]

78. Bakrania K, Edwardson CL, Bodicoat DH, Esliger DW, Gill JM, et al. (2016) Associations of mutually exclusive categories of physical activity and sedentary time with markers of cardiometabolic health in English adults: a cross-sectional analysis of the Health Survey for England. BMC Public Health 16:25. [Crossref]

79. Gibbs BB, Hergenroeder AL, Katzmarzyk PT, Lee IM, Jakicic JM (2015) Definition, measurement, and health risks associated with sedentary behavior. Med Sci Sports Exerc 47: 1295-1300. [Crossref]

Copyright: (C2017 Yamaga T. This is an open-access article distributed under the terms of the Creative Commons Attribution License, which permits unrestricted use, distribution, and reproduction in any medium, provided the original author and source are credited. 